\title{
Lactoferrin and Immunoglobulin Contents in Camel's Milk (Camelus bactrianus, Camelus dromedarius, and Hybrids) from Kazakhstan
}

\author{
G. Konuspayeva, ${ }^{*} \dagger$ B. Faye,$\dagger^{1}$ G. Loiseau, $\dagger$ and D. Levieux $\ddagger$ \\ *Kazakh State University Al Farabi, 71 av. Al-Farabi, 050013 Almaty, Kazakhstan \\ †Centre de Coopération International en Recherche Agronomique pour le Développement, \\ Campus international de Baillarguet TA 30/A, 34398 Montpellier cedex, France \\ †Institut National de la Recherche Agronomique, Qualité des Produits Animaux-Immunochimie, Theix, \\ 63122 Saint-Genes-Champanelle, France
}

\section{ABSTRACT}

Lactoferrin (Lf) and IgG were estimated in camel's milk from Kazakhstan, where 2 species of camels (Camelus bactrianus, Camelus dromedarius) and their hybrids cohabit. The concentrations of Lf and IgG were determined according to 3 variation factors: region $(\mathrm{n}=$ $4)$, season $(n=4)$, and species $(n=5$; sample 4 was mixed milk and sample 5 was of unknown origin). The mean values in raw camel's milk were $0.229 \pm 0.135$ $\mathrm{mg} / \mathrm{mL}$ for Lf concentration and $0.718 \pm 0.330 \mathrm{mg} / \mathrm{mL}$ for IgG concentration. The seasonal effect was the only significant variation factor observed, with the highest values in the spring for Lf and in the winter for IgG. The Lf concentration varied in 1 -wk postpartum milk from 1.422 to $0.586 \mathrm{mg} / \mathrm{mL}$. The range in IgG concentration was wide and decreased from 132 to $4.75 \mathrm{mg} / \mathrm{mL}$ throughout the $7 \mathrm{~d}$ postpartum, with an important drop after parturition. In fermented milk, the lactoproteins are generally hydrolyzed. For milk samples from undefined species, discriminant analyses did not allow the origin of the species to be determined. A slight correlation between Lf and IgG concentrations was observed in raw milk. The values were slightly higher than those reported in cow's milk, but this difference was insufficient to attribute medicinal virtues to camel's milk.

Key words: lactoferrin, immunoglobulin, camel's milk, colostrum

\section{INTRODUCTION}

The current camel population in Kazakhstan is around 130,000 head (Statistical Agency of the Republic of Kazakhstan, 2006). This country is well known for the cohabitation of 2 species of camels (Camelus bactrianus and Camelus dromedarius) and their hybrids. Within the Kazakh Bactrian breed, 3 types have

Received July 4, 2006.

Accepted August 24, 2006

${ }^{1}$ Corresponding author: faye@cirad.fr been described according to their geographic distribution: uralobukeevskii, kyzylordinskii, and yuzhnokazakhstanskii (Terenytev, 1975; Konuspayeva and Faye, 2004). For the Dromedary camel, only the Arvana breed, which originated from Turkmenistan, is present in Kazakhstan. Different levels of hybridation have occurred, resulting in a wide range of crossbreeds (Terenytev, 1975).

The consumption of camel's milk, especially in fermented form, is a very old tradition in Kazakhstan. Many beneficial properties are attributed to camel's milk and to a fermented product called shubat. It is traditionally used for the treatment of tuberculosis, gastroenteritis, and for many infections, and is also drunk as a tonic (Sharmanov and Dzhangabylov, 1991). These antimicrobial properties of camel's milk and shubat can be attributed to substances such as proteins, lipids, and vitamins (Elagamy et al., 1992; Farah, 1993; Elagamy, 2000; Benkerroum et al., 2004; Konuspayeva et al., 2004). Among the milk proteins, lactoferrin (Lf), IgG, lactoperoxidase, lysozyme, and some peptides are the main components that have been implicated (Barbour et al., 1984; Duhaiman, 1988). However, the quantity of those components and their overall variability in camel's milk are not well documented. In the present study, we determined the Lf and IgG contents in raw and fermented camel's milk from C. bactrianus, C. dromedarius, and their hybrids under different seasonal and geographic conditions.

\section{MATERIALS AND METHODS}

\section{Sampling Procedure}

To obtain the maximum variability, the camel's milk was sampled from 4 different regions at extreme points of Kazakhstan: Almaty, Atyrau, Aralsk, and Shymkent (the maximum distance between the different points was more than $3,500 \mathrm{~km}$ ) and in 4 seasons of the year. In total, 128 samples were used for quantitative and qualitative determination of the Lf and IgG contents in camel's milk (Table 1). Those samples, collected ran- 


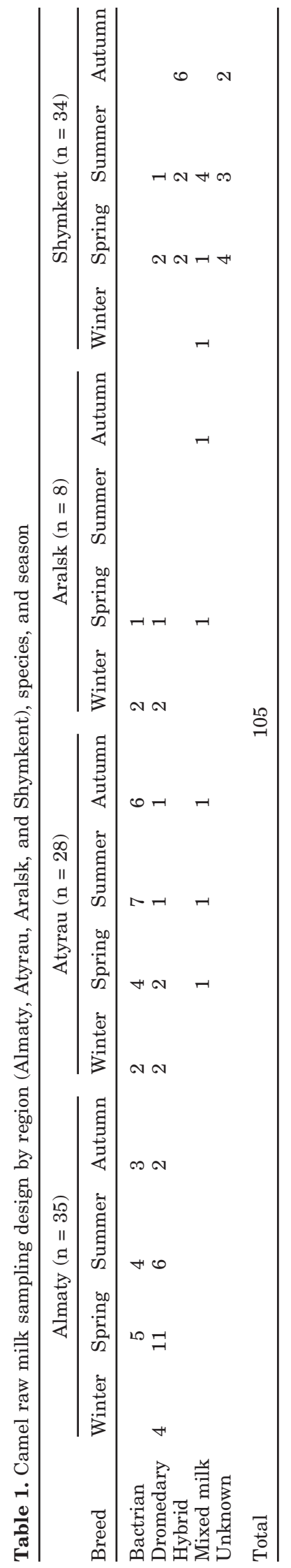

domly among lactating females on 2 private farms per region, comprised 105 raw milk samples, 6 colostrum samples, and 17 fermented milk samples (shubat). The raw milk samples were collected at milking time in Bactrian ( $\mathrm{n}=37)$, Dromedary $(\mathrm{n}=42)$, and hybrid $(\mathrm{n}=$ 6) animals. In some cases, samples were collected from different species after the whole milking ( $n=14$; hereafter referred to as "mixed milk"). In 6 cases, information on species origin was not available (hereafter referred to as "unknown"). Bactrian camel's milk samples were from different Kazakh types, as described above. Milk samples from Dromedary camels were from the Turkmen Arvana breed. Hybrid samples involved $\mathrm{F}_{1}$ or $\mathrm{F}_{2}$ crossbred animals. Milk samples collected within $8 \mathrm{~d}$ of parturition were called colostrum. The colostrum originated from the Almaty region; samples were collected from 6 Dromedaries in the spring only (i.e., in the main calving period for this area, from January to April). Shubat samples were collected, like the "mixed milk" samples, by region and season (Table 2). In all cases, milk was obtained by manual milking and kept frozen at $-20^{\circ} \mathrm{C}$ until analysis.

\section{Reference Materials for Laboratory Analysis}

Noble Agar was supplied by Difco (Detroit, MI). Bovine serum albumin, trichlo-trifluoroethane, and Freund's complete and incomplete adjuvants were purchased from Sigma-Aldrich (Saint Quentin Fallavier, France). Individual colostrum samples, used for protein purification, were obtained from lactating camels $(C$. dromedarius) at the Experimental Station of the Arid Land Institute of Medenine (Tunisia).

For protein purification, colostrum was first defatted by centrifugation at $2,500 \times g$ for $30 \mathrm{~min}$ and diluted 3.5 -fold ( vol/vol) with distilled water. Caseins were then precipitated by decreasing the $\mathrm{pH}$ to 4.2 with $1 \mathrm{M} \mathrm{HCl}$. After centrifugation at $20,000 \times g$ and $4^{\circ} \mathrm{C}$ for $20 \mathrm{~min}$, the supernatant was dialyzed overnight against 0.02 $M$ Tris-HCl buffer ( $\mathrm{pH}$ 8.4) and centrifuged at 20,000 $\times g$ and $4^{\circ} \mathrm{C}$ for $30 \mathrm{~min}$.

\section{Purified Proteins}

Immunoglobulin $\mathrm{G}$ was purified as previously described (El-Hatmi et al., 2006). Briefly, IgG was obtained from camel colostrum by a combination of gel permeation chromatography on Sephadex G200 (Amersham Biosciences, Orsay, France) and ion-exchange chromatography on Q-Sepharose Fast Flow (Amersham).

For the purification of Lf, the third peak obtained by gel permeation chromatography of colostral whey on Sephadex G200 equilibrated in 0.02 $M$ Tris-HCl buffer 
Table 2. Fermented camel's milk (shubat) sampling design by region and season

\begin{tabular}{lllll}
\hline Region & Winter & Spring & Summer & Autumn \\
\hline Almaty & 1 & 2 & & 1 \\
Atyrau & & 2 & 2 & 2 \\
Aralsk & 3 & & 1 & \\
Shymkent & 1 & 2 & 17 & \\
Total & & & & \\
\hline
\end{tabular}

( $\mathrm{pH}$ 8.6) was passed through a 5-mL HiTrap heparin column (Amersham Biosciences) and equilibrated in the same buffer. Elution was performed at $2 \mathrm{~mL} / \mathrm{min}$ over a 0 to $1 M \mathrm{NaCl}$ gradient $(60 \mathrm{~mL})$ using HPLC equipment (pump 420, detector 430; Kontron Instruments, StQuentin-en-Yvelines, France). Lactoferrin eluted as a single peak at $0.3 \mathrm{M} \mathrm{NaCl}$. Purity was checked by polyacrylamide gel electrophoresis ( $12.5 \%$ acrylamide) with or without denaturing agents (SDS and mercaptoethanol with heating for $5 \mathrm{~min}$ in a boiling water bath).

\section{Polyclonal Antibodies}

Rabbits were immunized at monthly intervals by multiple intradermal injections of antigen-adjuvant mixture (Levieux et al., 2005) prepared by emulsifying $1 \mathrm{vol}$ of saline containing 0.5 to $1 \mathrm{mg}$ of purified protein/ $\mathrm{mL}$ and $1 \mathrm{vol}$ of complete (first injection) or incomplete (booster injections) Freund's adjuvant. Each rabbit received $2 \mathrm{~mL}$ of the emulsion. Animals were bled $7 \mathrm{~d}$ after each booster injection and the sera were analyzed for antibody activity and specificity by immunoelectrophoresis (Scheidegger, 1955) and single radial immunodiffusion assay (SRID; Mancini et al., 1965). The immunogens used were purified IgG and Lf.

\section{Immunochemical Assay of Proteins}

Concentrations of IgG and Lf in individual colostrum and milk samples were determined by the SRID assay using 1.9-mm-thick agar plates containing $1.2 \%$ agar in $0.005 M$ barbital buffer ( $\mathrm{pH} 7.3$ ) and suitable quantities of each specific antiserum, as described by Levieux (1991) and adapted for Lf determination according to Levieux et al. (2005). Circular wells (1.5-mm diameter) were punched out of the gel and filled with $3-\mu \mathrm{L}$ aliquots of adequately diluted samples or $3 \mu \mathrm{L}$ of purified proteins of known concentration as standards. The purified proteins and samples were diluted in the barbital buffer containing $1 \%$ nonimmunized rabbit serum and $1 \mathrm{mg}$ of sodium azide/mL. Plates were incubated in a moist box at $37^{\circ} \mathrm{C}$ for 15 to $20 \mathrm{~h}$, and the diameter of the ringshaped precipitates was measured using a magnifying video camera system (Levieux, 1991). Standard curves were constructed by plotting the diameter of the precipitating ring vs. the square root of the protein concentration. With the diffusion time used, a linear regression was always obtained. Samples and standards were plated in duplicate. The coefficients of variation of the assays were 3 to $5 \%$.

\section{Statistical Analysis}

A linear model was tested, with IgG and Lf concentrations as dependent variables. The tested variation factors were region, species, season, and their interactions. The significance level for the variance analysis was set at 0.05 . The results are presented as mean \pm standard error. Because the variances were not homogeneous, data were log-transformed to attain a normal distribution of values. The correlation between Lf and IgG was tested using a Pearson correlation. To identify the factors linked to low and high values for IgG and Lf simultaneously, the samples were divided into IgG1 and Lf1 (concentrations below the median values) and IgG2 and Lf2 (concentrations above the median values), giving 4 groups of samples (IgG1/Lf1, IgG2/Lf1, IgG1/Lf2, and IgG2/Lf2). The partitioning into those groups by species, season, and region was evaluated by a $\chi^{2}$ test. Separate analyses were conducted for raw camel's milk, colostrum, and shubat. The R software was used for all statistical analyses (Ihaka and Gentleman, 1996).

\section{RESULTS}

\section{Camel Raw Milk Samples}

Lf Content. The mean Lf concentration in raw camel's milk was $0.229 \pm 0.135 \mathrm{mg} / \mathrm{mL}$. According to geographic factors, the Lf content was higher, on average, in the Shymkent region (Table 3), but the differences were not significant (Table 4). Also, no significant differences were found among species in spite of the higher mean Lf content in hybrids (Tables 3 and 4). The ANOVA showed a significant seasonal effect (Table 4) only for Lf $(P<0.05)$, with the Lf content being higher in the spring $(0.271 \pm 0.161 \mathrm{mg} / \mathrm{mL})$ than in the autumn $(0.176 \pm 0.083 \mathrm{mg} / \mathrm{mL}$; Table 4$)$.

Because the seasonal effect was significant, the monthly changes in Lf concentration are shown (Figure 1). Peak Lf concentrations were clearly observed in April $(0.294 \pm 0.152 \mathrm{mg} / \mathrm{mL})$ and in June $(0.312 \pm 0.194$ $\mathrm{mg} / \mathrm{mL} ; P<0.05)$. The lowest Lf concentrations were observed from July to October $(0.190 \pm 0.072 \mathrm{mg} / \mathrm{mL})$.

IgG Content. The mean IgG concentration in raw camel's milk was $0.718 \pm 0.330 \mathrm{mg} / \mathrm{mL}$. The IgG content was, on average, higher in the Aralsk region (Table 3), but like Lf, the differences were not significant (Table 4). Also, no significant difference was found for species 
Table 3. Mean \pm standard error of lactoferrin (Lf) and IgG content (in $\mathrm{mg} / \mathrm{mL}$ ) in camel raw milk according to the region, season, and species

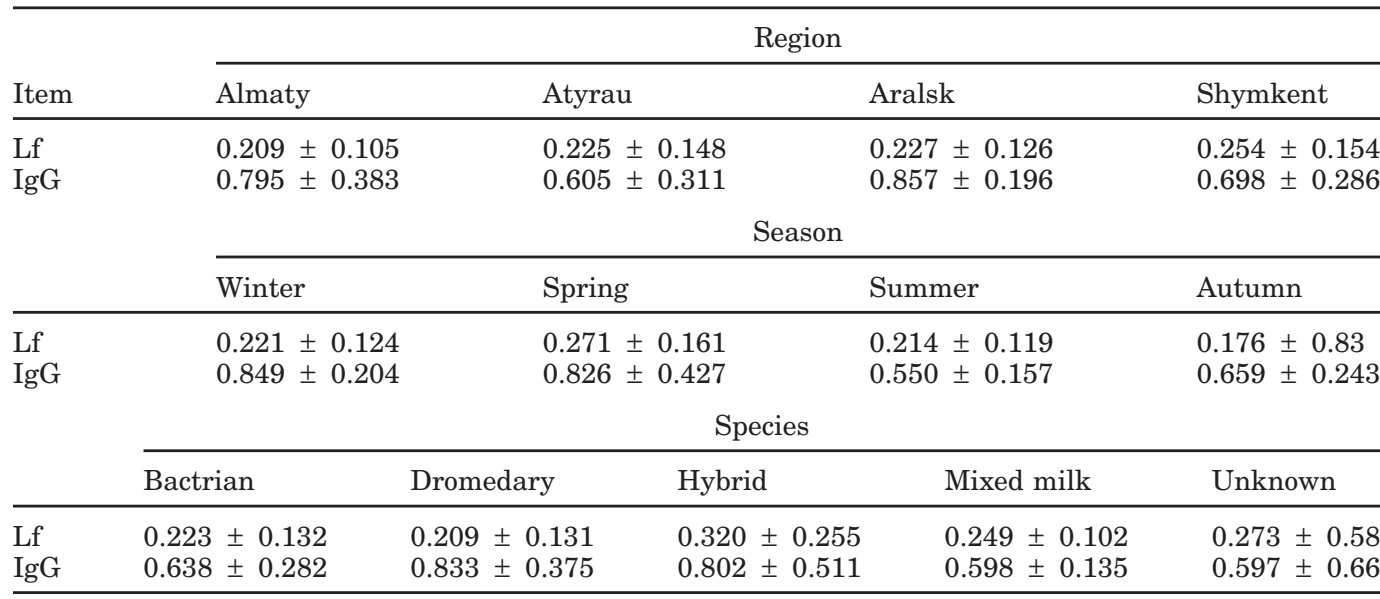

in spite of the higher mean IgG concentration in the Dromedary (Tables 3 and 4). Similar to Lf, the seasonal change in IgG content was significant $(P<0.001)$, with higher values in the winter $(0.849 \pm 0.204 \mathrm{mg} / \mathrm{mL})$ than in the summer $(0.550 \pm 0.157 \mathrm{mg} / \mathrm{mL}$; Table 4$)$. There was a significant interaction $(P<0.01)$ between region and species for IgG concentration, which can be explained by the significantly higher IgG concentration in Dromedary raw camel's milk samples from Aralsk $(0.955 \pm 0.243 \mathrm{mg} / \mathrm{mL})$ compared with the Bactrian samples from Almaty $(0.591 \pm 0.128 \mathrm{mg} / \mathrm{mL})$.

The monthly change in IgG concentration is shown (Figure 2). The IgG concentration decreased regularly $(P<0.001)$ throughout the year, with the highest value found in January $(0.975 \pm 0.132 \mathrm{mg} / \mathrm{mL})$ and the lowest in July $(0.511 \pm 0.121 \mathrm{mg} / \mathrm{mL})$.

\section{Correlation Between Lf and IgG}

The correlation between IgG and Lf concentrations in all raw camel's milk samples was significant $\left(\mathrm{r}^{2}=\right.$ $0.530, P<0.01)$. The regression equation was

$$
[\operatorname{IgG}]=421+1,295[\mathrm{Lf}] \varepsilon=281 .
$$

The number of milk samples from Bactrian and Dromedary camels was sufficient to compare the regression lines (Figure 3). The Pearson correlation coefficient was significant for the Bactrian camel $\left(\mathrm{r}^{2}=0.706, P<0.05\right)$, mainly because of few samples having a high concentration of both Lf and IgG, but not for the Dromedary $\left(\mathrm{r}^{2}=\right.$ 0.327 , NS). However, after omitting a single outstanding point, the Pearson correlation coefficient for the Bactrian camel was still significant $\left(\mathrm{r}^{2}=0.340, P<0.05\right)$.

Based on their concentrations of both Lf and IgG (Table 5), the 4 groups of samples were significantly linked $(P<0.001)$ to some factors: The samples with low concentrations of both IgG and Lf (IgG1/Lf1) were linked to summer milk from the Dromedary at Shymkent, whereas the samples with high concentrations of both IgG and Lf (IgG2/Lf2) were linked to spring milk from the Bactrian at Atyrau. The group IgG1/Lf2 was more frequent in summer milk from the Dromedary, whatever the region, and the group IgG2/Lf1 was more

Table 4. $F$-value and probability level from ANOVA for the lactoferrin (Lf) and IgG contents of camel raw milk.

\begin{tabular}{lllll}
\hline \multirow{2}{*}{$\begin{array}{l}\text { Factors and their } \\
\text { interactions }\end{array}$} & \multicolumn{2}{c}{ Lf } & & IgG \\
\cline { 2 - 5 } & $F$-value & $P(>F)$ & & $F$-value \\
\hline Region & 1.138 & 0.289 & 0.472 & 0.494 \\
Season & 5.685 & $0.019 *$ & 12.480 & $0.001^{* * *}$ \\
Species & 1.781 & 0.185 & 0.105 & 0.747 \\
Region $\times$ season & 1.330 & 0.252 & 2.049 & 0.156 \\
Region $\times$ species & 0.035 & 0.852 & 7.275 & $0.008^{* *}$ \\
Season $\times$ species & 1.064 & 0.305 & 1.539 & 0.218 \\
Region $\times$ season $\times$ species & 0.191 & 0.663 & 1.102 & 0.297 \\
\hline
\end{tabular}

$* P<0.05 ; * * P<0.01 ; * * * P<0.001$. 


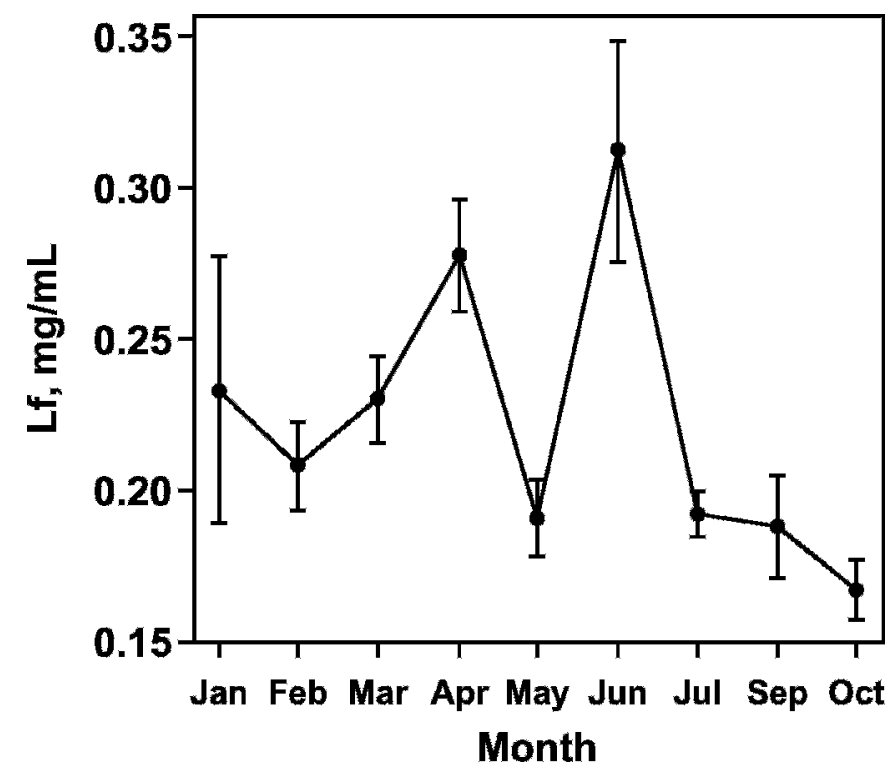

Figure 1. Monthly changes (mean $\pm \mathrm{SE}$ ) in the lactoferrin (Lf) content of raw camel's milk.

common in spring milk from Aralsk, whatever the species.

\section{Colostrum Samples}

Six samples of colostrum were collected, in 2 time repetitions on $\mathrm{d} 7$ after parturition. The Lf concentration varied from 1.422 to $0.586 \mathrm{mg} / \mathrm{mL}$ throughout the

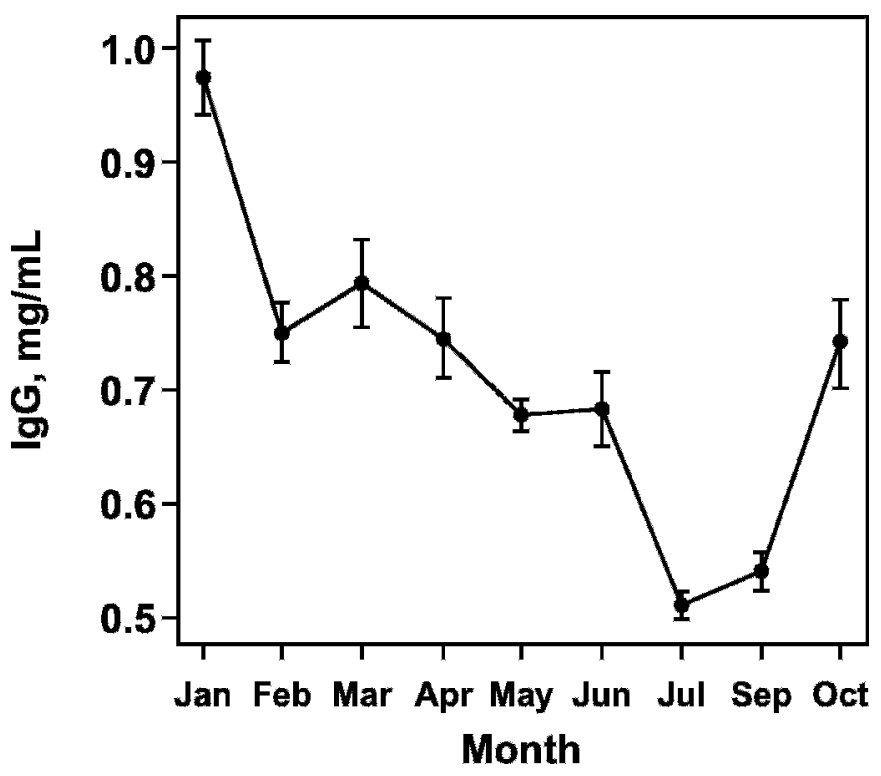

Figure 2. Monthly changes (mean $\pm \mathrm{SE}$ ) in the IgG content of raw camel's milk.

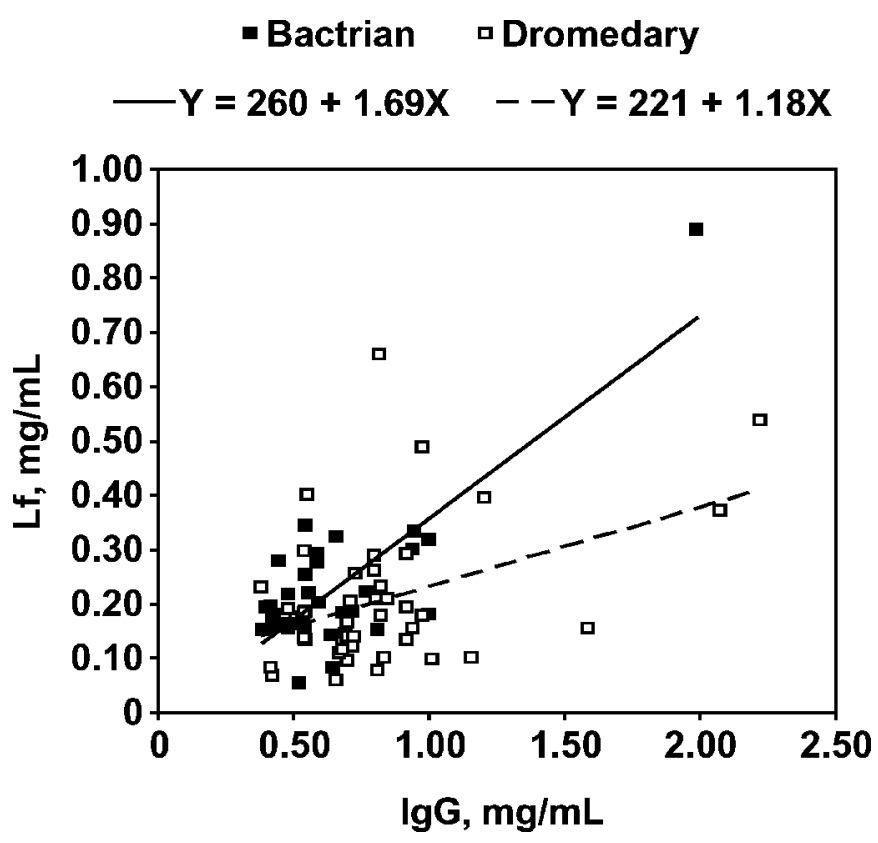

Figure 3. Relationships between the IgG and lactoferrin (Lf) concentrations in Bactrian ( $\square$ ) and Dromedary ( $\square$ ) camel's milk, and regression lines for the Bactrian (-) and Dromedary (- ) breeds.

$7 \mathrm{~d}$ postpartum. This concentration did not decrease as did the IgG concentration, but the quantity was, on average, $0.813 \pm 0.311 \mathrm{mg} / 100 \mathrm{~mL}$ (i.e., more than 3 times higher than in milk samples; Figure 4). The range of IgG concentrations in the colostrum samples was wide (from 132.563 to $4.750 \mathrm{mg} / \mathrm{mL}$ ), with an important decrease after parturition (Figure 5).

\section{Shubat Samples}

In total, 17 samples of fermented camel's milk (shubat) were collected from different regions and seasons, and were quantified for Lf and IgG contents. However, for some samples the appearance of the ring-shaped precipitate with the SRID technique was indicative of Lf or IgG proteolysis occurring during the fermentation process. Thus, the Lf concentration was determined in 9 samples (values between 0.037 and $0.571 \mathrm{mg} / \mathrm{mL}$ ) and IgG in 3 cases (values between 0.344 and $0.719 \mathrm{mg} / \mathrm{mL}$ ).

Table 5. Immunoglobulin $\mathrm{G}$ and lactoferrin (Lf) concentration (mg/ $\mathrm{mL}$, mean $\pm \mathrm{SE}$ ) in each group of samples according to the values below (IgG1, Lf1) or above (IgG2, Lf2) the median value

\begin{tabular}{lll}
\hline Sample & IgG concentration & Lf concentration \\
\hline Group IgG1/Lf1 & $0.513 \pm 0.96$ & $0.142 \pm 0.42$ \\
Group IgG1/Lf2 & $0.523 \pm 0.77$ & $0.270 \pm 0.51$ \\
Group IgG2/Lf1 & $0.880 \pm 0.323$ & $0.146 \pm 0.56$ \\
Group IgG2/Lf2 & $0.942 \pm 0.397$ & $0.358 \pm 0.174$ \\
\hline
\end{tabular}




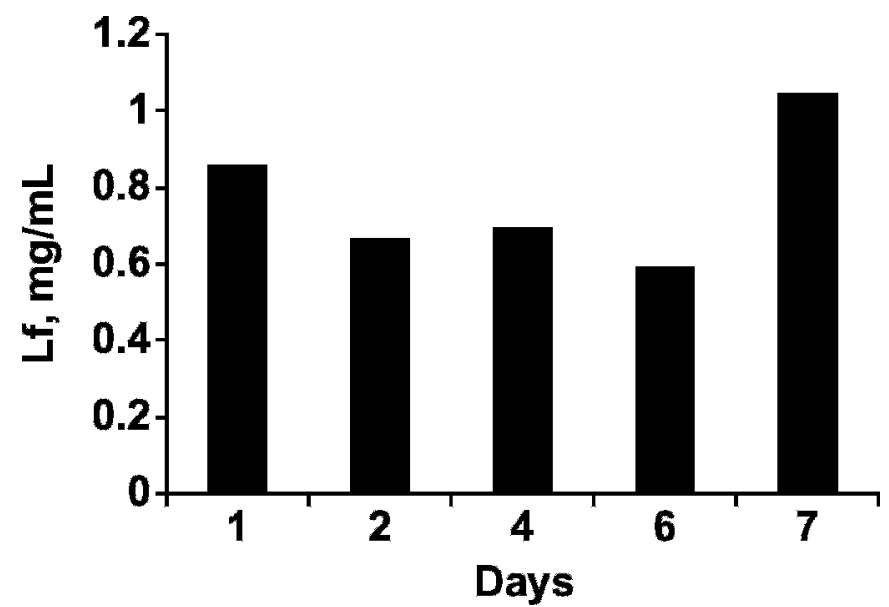

Figure 4. Changes in the lactoferrin (Lf) concentration in colostrum samples from the Dromedary after parturition.

\section{DISCUSSION}

\section{Sampling Procedure}

The sampling design aimed to optimize the variability in milk composition according to the main variation factors generally described in the literature: species (single- or double-humped camels and their hybrids), region (including farming practices and feeding systems), and season (including the feeding system and physiological status as the calving period occurred between January and April). However, because of the long distances between regions and harsh conditions in the winter, and because of the specific presence of Bactrian or Dromedary camels in some regions, it was not possible to collect milk samples in some cases and to provide

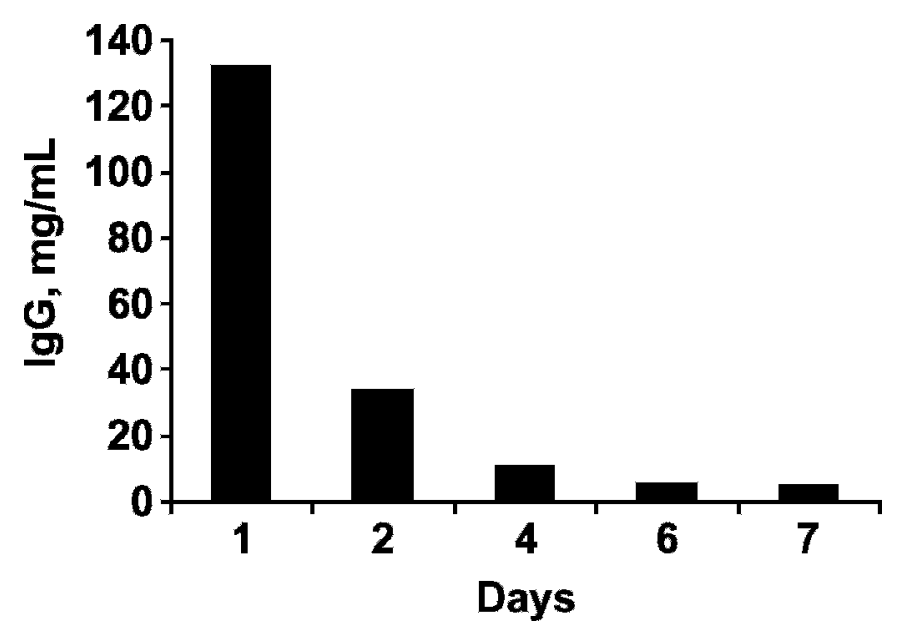

Figure 5. Changes in the IgG concentration of colostrum samples from the Dromedary after parturition.
Table 6. Concentration of lactoferrin in camel's milk (in $\mathrm{mg} / \mathrm{mL}$ ) according to the literature

\begin{tabular}{lll}
\hline Reference & $\begin{array}{l}\text { Minimum } \\
\text { value }\end{array}$ & $\begin{array}{l}\text { Maximum } \\
\text { value }\end{array}$ \\
\hline Qian (1995) & 2.000 & 6.000 \\
El-Gawad et al. (1996) & & 2.480 \\
Elagamy et al. (1996) & 0.020 & 0.080 \\
Zhang et al. (2005) & 2.350 & 7.280 \\
El-Hatmi (2006) & 0.140 & 0.420 \\
Present results & 0.055 & 0.888 \\
\hline
\end{tabular}

${ }^{1}$ Expressed as the percentage of total proteins for the Bactrian camel only.

information for all the cells (species $\times$ region $\times$ season). Thus, our sampling design was unbalanced because of field constraints. Because some cells were not informed or had a limited number of samples, nonsignificant results could have been due to a lack of statistical power and to questionable results.

\section{Laboratory Methods}

The methods used in the present study were tested all along the process to control the critical points at each step. The analytical method retained was that of Mancini (1965), as modified by Levieux (1991). For determination, the Lf and IgG proteins were purified by classical methods (ion-exchange chromatography) and then controlled for purity. Rabbits were immunized against camel Lf and camel IgG to obtain polyclonal antibodies. Those antibodies were tested by the method of Ouchterlony (Mancini et al., 1965) with standard solutions of proteins and also other milk proteins to see whether the polyclonal serum presented another immunity activity to other proteins. The specificity of the anti-Lf-camel and anti-IgG-camel activity was tested with controlled bovine polyclonal antibodies. Finally, the polyclonal serum was tested by immunoelectrophoresis (Levieux et al., 2005; El-Hatmi et al., 2006). After these tests, the methods used were determined to be adequate to describe variations in the $\mathrm{Lf}$ and IgG concentrations.

\section{Lf Concentrations in Milk and Colostrum}

The Lf concentration increased in spring milk. The main reason could be a better quality of pasture from March to June, but no data are available in the literature on the effect of feeding on camel's milk composition. Most of the animals sampled in the spring were probably at the beginning of lactation, when the protein content in milk is generally higher.

Some studies of the Lf content in camel's milk have shown different concentrations of this protein (Table 6). However, the authors have used different methods 
for quantitative analyses and different units, and sometimes the analytical methods have not been clearly described. Thus, comparisons with our data were quite difficult most of the time, and some results could be debatable.

For example, to determine the Lf concentration in Bactrian camel's milk, Zhang et al. (2005) used SDSPAGE and densitometry. All the results are presented as the percentage of total proteins. According to the authors, Lf represented between 2.35 and $7.28 \%$ of the total protein in the milk. Those results are quite different from our findings. Indeed, related to the total protein content of the Bactrian milk samples (results not presented), the Lf concentration represented 0.121 to $1.33 \%$ of total protein $($ mean $=0.424 \pm 0.217 \%)$. More generally, the Lf concentration in Bactrian camel's milk has rarely been studied. Our results showed that there was no significant difference between the Bactrian and Dromedary species. The Lf concentration seemed, on average, very high in milk from hybrids, but the variability was also more important than in pure species and the difference was not significant. In fact, the hybrid population was very heterogeneous. In Kazakhstan, 2 hybridizing schema are described (Kurt-Nar and Kez-Nar) according to the male sex in the Bactrian $\times$ Dromedary cross (Terenytev, 1975). In our sampling, no information on the hybridizing schema and generation $\left(\mathrm{F}_{1}, \mathrm{~F}_{2}\right.$, or $\left.\mathrm{F}_{3}\right)$ was available.

Elagamy (2000) used laboratory methods similar to ours but did not refer to the same authors as those cited here. The Lf concentration in Dromedary camel's milk reported by Elagamy (2000) was somewhat lower than our results $(0.170$ vs. $0.209 \mathrm{mg} / \mathrm{mL})$. According to recent results from El-Hatmi et al. (2006) using the same method as in the present study, the Lf concentration in Dromedary camel's milk from Tunisia was $0.140 \pm$ $0.002 \mathrm{mg} / \mathrm{mL}$, which is, on average, lower than our results $(0.209 \pm 0.135 \mathrm{mg} / \mathrm{mL})$. In late-lactation Dromedary camel's milk, Kappeler et al. (1999) found a similar Lf concentration $(0.22 \mathrm{mg} / \mathrm{mL})$.

Camel's milk has been renowned for its rich Lf content, compared with cow's milk, since the data of ElGawad et al. (1996) were published. According to those authors, the Lf concentration in raw camel's milk was higher $(2.48 \mathrm{mg} / \mathrm{mL})$ than in cow's milk (0.07 to 0.28 $\mathrm{mg} / \mathrm{mL}$, depending on the breed of cow). However, their data were based on HPLC analyses obtained with very few animals. Our results in the Dromedary camel ( 0.059 to $0.659 \mathrm{mg} / \mathrm{mL}$ ) also appeared slightly higher but in a lower proportion. In a comparison published by Elagamy (2000), the Lf concentration in cow's milk (0.0767 $\pm 0.022 \mathrm{mg} / \mathrm{mL}$ ) was also lower than in Dromedary camel's milk $(0.170 \pm 0.021 \mathrm{mg} / \mathrm{mL})$. Those results differed slightly from the results of other authors, who showed that the Lf concentration in cow's milk comprised only between 0.05 and $0.15 \mathrm{mg} / \mathrm{mL}$ (Rainard et al., 1982; Xiuyun and Yoshida, 1995), values that are closer to those observed by El-Hatmi et al. (2006) in the Dromedary camel. In the study by Kappeler (1998), the Lf concentration was, on average, $0.220 \mathrm{mg} / \mathrm{mL}$ in the camel and 0.140 in the cow.

The Lf content in colostrum is richer than that in mature milk in most species (Kappeler, 1998). El-Hatmi et al. (2006) found a range between 0.74 and $1.67 \mathrm{mg} /$ $\mathrm{mL}$ in colostrum of the Dromedary camel from Tunisia, with a significant decrease in Lf concentration after d 8 . Those values are comparable to our results $(0.58$ to $1.42 \mathrm{mg} / \mathrm{mL}$ ), and we observed a similar change in the first week postpartum. Those values are considerably lower than those published by El-Gawad et al. (1996) of $5.10 \mathrm{mg} / \mathrm{mL}$, on average, in 0 - to 2 -d camel's milk. Only Mahfouz et al. (1997) found more Lf in milk (1.42 $\mathrm{mg} / \mathrm{mL})$ than in colostrum $(0.13 \mathrm{mg} / \mathrm{mL})$.

In the Bactrian camel, Zhang et al. (2005) found a Lf concentration in colostrum of between 2.88 and $4.82 \%$ of total proteins. In our results it was between 0.32 and $2.43 \%$ (mean $1 \pm 0.73$ ), which is quite different.

The Lf concentration in camel colostrum $(0.586$ to $1.422 \mathrm{mg} / \mathrm{mL}$ in our results) seemed comparable to that in cow's colostrum: 0.64 to $4.2 \mathrm{mg} / \mathrm{mL}$ (El-Gawad et al., 1996). According to different authors cited by El-Hatmi et al. (2006), the Lf concentration in cow's colostrum constituted between 1.0 and $4.0 \mathrm{mg} / \mathrm{mL}$.

\section{IgG Concentration in Milk and Colostrum}

The IgG concentration in milk was higher in the winter. The main calving season was between January and March or April. At the beginning of lactation, the milk is known to be richer in IgG even if the colostrum is not taken into account, as in our study. The regular decrease in IgG concentration could probably not be linked only to a dilution effect by increasing milk production in the spring, compared with the winter. First, the dairy yield was low throughout the year, especially for the Bactrian camel. Second, the more favorable seasons were spring and autumn, but the lowest concentrations were found in summer. No seasonal variation of IgG concentration was reported in published papers on camel's milk.

Like Lf, the importance of IgG in camel's milk has been emphasized by many authors to explain the health effects of camel's milk (Sawaya et al., 1984; Elagamy et al., 1992; Farah, 1993; Konuspayeva et al., 2004). The IgG concentration is very high after parturition. In a previous study of the Tunisian camel (El-Hatmi et al., 2006), the IgG concentration at the first milking was between 11.8 and $211.1 \mathrm{mg} / \mathrm{mL}$ (mean $100.7 \pm 60.4$ 
$\mathrm{mg} / \mathrm{mL}$ ), which is comparable to the $132.5 \mathrm{mg} / \mathrm{mL}$ found in the only milk sample obtained at the first milking in our survey. This concentration fell sharply but the level stayed above $4.82 \mathrm{mg} / \mathrm{mL}$ at $\mathrm{d} 7$. This trend was similar to those described by El-Hatmi et al. (2006) and Elagamy (1998). Of course, our results were obtained from different animals, in contrast to those in the references mentioned. However, our results are consistent with other data published on camel colostrum (UngarWaron et al., 1987). On average, the IgG concentration in camel colostrum seemed to be higher than that in other species (El-Hatmi et al., 2006). In the Bactrian camel, Zhang et al. (2005) mentioned that IgG represented 0.90 to $2.52 \%$ of the total proteins from $\mathrm{d} 1 \mathrm{up}$ to $d$ 7. In our results, the IgG was between 6.6 and $49.1 \%$ (mean $19.5 \pm 17.1 \%$ ) of the total protein. The results of Zhang et al. (2005) could be debatable, possibly because of a misreading of the SDS-PAGE owing to the segmentation into $\mathrm{H}$ and $\mathrm{L}$ chains of IgG.

In the study by Elagamy (2000), the IgG concentration in late-lactation camel's milk was higher than that in our results ( $2.217 \mathrm{vs.} 0.718 \mathrm{mg} / \mathrm{mL}$ ). In any case, those values appeared higher than the IgG concentration observed in cow's milk: $0.520 \pm 0.064 \mathrm{mg} / \mathrm{mL}$ (Elagamy, 2000). In the Bactrian camel, the IgG concentration was 0.65 to $1.60 \%$ of total protein (Zhang et al., 2005 ), comparable to our data (0.61 to $2.97 \%$; mean $1.24 \pm 0.53 \%)$.

\section{Lf and IgG Correlation}

To our knowledge, no data showing the correlation between Lf and IgG in camel's milk is available in the literature. The observed correlation in our results was significant, but some milk samples were rich in both LF and IgG. Those rare milk samples allowed us to build a regression line, but with a high error type. Most of those samples were spring milk from the Bactrian breed at Atyrau, close to the Caspian Sea. Omission of those outstanding points led to a lower correlation coefficient (0.34), which is at the limit of the significant level. It is probably more convenient to consider different types of milk with high concentrations of Lf and IgG compared with poor milk (low concentrations of both proteins), as we proposed.

\section{Lf and IgG in Shubat}

The fermentation process leads to the degradation of proteins in the milk. In Kazakhstan, traditionally the milk is not heated before the fermentation process. Thus, the observed degradation cannot be attributed to heat denaturation. Elsewhere, the ring-shaped precipitates observed with shubat samples were very pale, which is characteristic of proteolysis, as has been observed in comparison with heat-treated samples (Levieux et al., 2005). In shubat, Lf and IgG are probably mainly hydrolyzed into polypeptides with similar antigenic properties as the original protein. This degradation is increased with the age of the shubat. Moreover, the technology for shubat fermentation is neither controlled nor standardized. Thus, the degree of fermentation is not known (i.e., the importance of the protein hydrolyzing). With the method of Mancini et al. (1965) for SRID, the antibodies, and the standards used in the current study, it was not possible to take in account the content of polypeptides and to differentiate them from the original proteins. The values obtained in some samples from our study could be attributed to "young" shubat at the beginning of the protein degradation process. No data on this process are available in the literature.

\section{CONCLUSIONS}

Lactoproteins such as Lf and IgG are known as health factors that play an important role for milk consumers. In particular, camel's milk, which is consumed in many countries (such as Kazakhstan) for its medicinal virtues, is renowned for being richer in some lactoproteins compared with cow's milk. In fact, the concentrations of Lf and IgG in camel's milk seem to be only slightly higher than those in other milks. However, this quantitative difference does not explain the highly renowned quality of camel's milk. The quantity of those proteins is probably not the only aspect particular to camel's milk. Other proteins such as lysozyme, lactoperoxidase, and growth factors could be linked to its health effects.

Our results showed that the difference between Bactrian and Dromedary camel's milk was not clear with our observational design, and that the seasonal effect was more important than other variation factors. The seasonal effect is a complex factor that includes a camel's physiological status and feeding. However, these results are a first step toward explaining the observed variability in camel's milk.

\section{ACKNOWLEDGMENTS}

The study was supported by the French Ministry of Foreign Affairs (ECONET Programme) and by the French Embassy at Almaty (Kazakhstan). We thank also the Kazakh farmers for their continuing hospitality.

\section{REFERENCES}

Barbour, E. K., N. H. Nabbut, W. M. Frerichs, and H. M. Al Nakhli. 1984. Inhibition of pathogenic bacteria by camel's milk: Relation to whey lysozyme and stage of lactation. J. Food Prot. 47:838-840. 
Benkerroum, N., M. Mekkaoui, N. Bennani, and K. Hidane. 2004. Antimicrobial activity of camel's milk against pathogenic strains of Escherichia coli and Listeria monocytogenes. Int. J. Dairy Technol. 57:39-43.

Duhaiman, A. S. 1988. Purification of camel's milk lysozyme and its lytic effect on E. coli and Micrococcus lysodeikticus. Comp. Biochem. Physiol. 91b:793-796.

Elagamy, E. I. 1998. Camel's colostrums: Antimicrobial factors. Pages 227-232 in Proc. Workshop Dromadaires et chameaux, animaux laitiers. P. Bonnet, ed. CIRAD, Montpellier, France.

Elagamy, E. I. 2000. Effect of heat treatment on camel milk proteins with respect to antimicrobal factors: A comparison with cows' and buffalo milk proteins. Food Chem. 68:227-232.

Elagamy, E. I., R. Ruppanner, A. Ismail, C. P. Champagne, and R. Assaf. 1992. Antibacterial and antiviral activity of camel's milk protective proteins. J. Dairy Res. 59:169-175.

Elagamy, E. I., R. Ruppanner, A. Ismail, C. P. Champagne, and R. Assaf. 1996. Purification and characterization of lactoferrin, lactoperoxydase, lysozyme and immunoglobulins from camel's milk. Int. Dairy J. 6:129-145.

El-Gawad, I. A., E. M. El-Sayed, M. B. Mahfouz, and A. M. Abd ElSalam. 1996. Changes of lactoferrin concentration in colostrum and milk from different species. Egypt. J. Dairy Sci. 24:297-308.

El-Hatmi, H., A. Levieux, and D. Levieux. 2006. Camel (Camelus dromedarius) immunoglobulin $\mathrm{G}, \alpha$-lactalbumin, serum albumin and lactoferrin in colostrum and milk during the early post partum period. J. Dairy Res., doi:10.1017/S0022029906001713.

Farah, Z. 1993. Composition and characteristics of camel milk. J. Dairy Res. 60:603-626.

Ihaka, R., and R. Gentleman. 1996. A language for data analysis and graphics. J. Comput. Graph. 5:299-314.

Kappeler, S. R. 1998. Compositional and structural analysis of camel milk proteins with emphasis on protective proteins. $\mathrm{PhD}$ thesis no. 12947, Swiss Federal Institute of Technology (ETH), Zurich, Switzerland.

Kappeler, S. R., R. Ackerman, Z. Farah, and Z. Puhan. 1999. Sequence analysis of camel (Camelus dromedarius) lactoferrin. Int. Dairy J. 9:481-486.

Konuspayeva, G., and B. Faye. 2004. A better knowledge of milk quality parameters: A preliminary step for improving the camel milk market opportunity in a transition economy-The case of Kazakhstan. Pages 28-36 in Proc. Intl. Conf. "Saving the Camel and Peoples' Livelihoods," Sadri, Rajasthan, India, Nov. 23-25, 2004. LPPS Publ., Sadri, India.

Konuspayeva, G., G. Loiseau, and B. Faye. 2004. La plus-value "santé" du lait de chamelle cru et fermenté: L'Expérience du
Kazakhstan. Pages 47-50 in Proc. 11th Rencontre autour des Recherches sur les Ruminants, Institut National de la Recherche Agronomique, Paris, Dec. 8-9, 2004. Institut d'Elevage, Paris, France.

Levieux, D. 1991. Dosage des IgG du lait de vache par immunodiffusion radiale semi-automatisée, pour la détection du colostrum, des laits de mammites ou de fin de gestation. I. Mise au point du dosage. Lait 71:327-338.

Levieux, D., A. Levieux, H. El-Hatmi, and J. P. Rigaudière. 2005. Immunochemical quantification of heat denaturation of camel (Camelus dromedarius) whey proteins. J. Dairy Res. 72:1-9.

Mahfouz, M. B., E. M. El-Sayed, L. A. El-Gawad, H. El-Etriby, and A. M. Abd El-Salam. 1997. Structural studies on colostrum and milk lactoferrin from different species. Egypt. J. Dairy Sci. 25:41-53.

Mancini, G., A. O. Carbonara, and J. F. Heremans. 1965. Immunochemical quantification of antigens by single radial immunodiffusion. Immunochemistry 2:235-254.

Qian, Z. Y., P. Jollès, D. Migliore-Samour, and A. M. Fiat. 1995. Isolation and characterization of sheep lactoferrin, an inhibitor of platelet aggregation and comparison with human lactoferrin. Biochim. Biophys. Acta 1243:25-32.

Rainard, P., B. Poutrel, and J. P. Caffin. 1982. Lactoferrin and transferrin in bovine milk in relation to certain physiological and pathological factors. Ann. Rech. Vet. 13:321-328.

Sawaya, W. N., J. K. Khalil, A. Al-Shalhat, and H. Al-Mohammad. 1984. Chemical composition and nutritional quality of camel milk. J. Food Sci. 49:744-747.

Scheidegger, J. J. 1955. Une microméthode de l'immuno-électrophorèse. Int. Arch. Allergy Appl. Immunol. 7:103-110.

Sharmanov, T. S., and A. K. Dzhangabylov. 1991. Medical Properties of Kumis and Shubat (in Russian). Gylym, Almaty, Kazakhstan.

Statistical Agency of the Republic of Kazakhstan. 2006. Short Review of the Statistical Agency of the Republic of Kazakhstan: Socialeconomic Development of Kazakhstan. Almaty, Kazakhstan.

Terenytev, C. M. 1975. Camel Farming (in Russian). Kolos, Moscow, Russia.

Ungar-Waron, H., E. Elias, A. Gluckman, and Z. Trainin. 1987. Dromedary IgG: Purification, characterization and quantification in sera of dams and newborns. Israel J. Vet. Med. 43:198-203.

Xiuyun, Y. E., and S. Yoshida. 1995. Lactoperoxidase and lactoferrin: Changes in post partum milk during bovine lactational disorders. Milchwissenschaft 50:67-70.

Zhang, H., J. Yao, D. Zhao, H. Liu, J. Li, and M. Guo. 2005. Changes in chemical composition of Alxa Bactrian camel milk during lactation. J. Dairy Sci. 88:3402-3410. 